\title{
An Analysis of Key Factors to Mobile Health Adoption using Fuzzy AHP
}

\author{
Farhad Lotfi and Kimia Fatehi \\ Department of Information Technology Engineering, South Tehran Branch, Islamic Azad University, Tehran, Iran \\ E-mail: st_f_lotfi@azad.ac.ir, fatehikimia@gmail.com \\ Nasrin Badie* \\ Department of Information Technology Software Development, School of Engineering, West Tehran Islamic Azad \\ University, Shahid Hasan Azari St, Ashrafi Esfahani Expy, Tehran, Iran \\ E-mail: Nasrin.badie@gmail.com
}

Received: 21 December 2019; Accepted: 01 January 2020; Published: 08 April 2020

\begin{abstract}
In the present era, ICT has brought significant facilities for the growth and innovation of organizations. Thus, with the advent of information technology in the field of healthcare, significant advances have been made in terms of the high level of care in preventing a variety of diseases and treatments as well. Mobile health, which is a part of smart health concept, helps people, at any time and place, use smart devices such as smartphones, smart watches, and the like to monitor their health status like pulse, blood pressure and so on. Therefore, this article aims to examine the effective factors on the adoption of mobile health technology. According to the field of research and the number of people considered, this study examined some of the factors affecting the adoption of mobile health technology among 19 expert experts who have mainly researched in this field. This research uses the Fuzzy AHP method. The main factors for admitting mobile health technology were divided into five main categories, including system quality, information quality, individual factors, service quality, and organizational quality. The results indicated that system quality, quality of information and individual factors have more impact on the acceptance of mobile health technology than service quality and organizational factors. In addition, according to the results obtained in this study, mobile health can be used as the most reliable and safest tools to control and monitor diseases. Ultimately, experts emphasized the need to use mobile health technology continuously.
\end{abstract}

Index Terms-Mobile Health, Fuzzy AHP, Smart Healthcare, Smart City.

\section{INTRODUCTION}

Today, there is a growing population in cities and metropolises in the world, as well as immigration and many travels. Hence, it is necessary to pay special attention to the healthcare issue in order to make better policy and management. Furthermore, it should be noted that it is no longer possible to manage the huge flood of diseases added every day and improve the status of patients, through traditional ways. Thus, cities need to move towards being smart in order to identify challenges, threats, and opportunities and get the best solution for health planning based on ICT knowledge in both the scientific and industrial environment. The issue of smart health has recently attracted much attention in the scientific and industrial areas, as well as a good vision for it since it deals with better life-style development [1]. Mobile health, which is a puzzle of smart health, reduces costs and deals with the quality of services in this area subsequently [2].

It is necessary to address the issue of smart health since Groves, Kayyali [3] indicates that successful implementation of some cases, such as "prevention of disease, etc." can lead to $\$ 300$ to 450 billion cost savings and productivity only in the United States.

Healthcare services must have their own precision and elegance since if the quality is not considered, there will be bad consequences for patients and this also threatens the community. Zhan and Miller [4] argue that medical errors and mistakes have irreparable consequences as 32,000 people die annually in the world due to drugrelated errors; patients should stay in the hospital for 2.4 million extra days, and so on. The study adds that during hospitalization, family members are affected and the psychological and financial damage inflicted on those close to the patient that it exacerbates losses. Thus, it is clear that if being smart becomes pervasive, these problems and losses will be minimized. The issue of mobile health has attracted more attention in recent decades. Mobile health generally refers to a service plan of the type with devices such as mobile phones and others to provide healthcare to anyone at anytime, anywhere [5]. Mobile health aims to provide healthcare services to patients, doctors and other users with support services to manage, disseminate, collect information, monitor and control health information and improve the quality of healthcare services.

Services are provided by health information systems. These services reduce the geographical and temporal 
constraints while improving the quality of patient care, cost savings, and other benefits of healthcare [6]. The need for mobile health associated with information services can include patient care, community health, and self-care, physicians' decision-making on how to work with the patient and providing patient information to recipients of services and service providers $[7,8]$.

The analysis approach in this paper is based on one of the most important tools introduced by Lotfi Zadeh [9] and Fuzzy logic. In this paper, the analytical approach of [10], has been used which has benefited from Fuzzy AHP.

Recently, many improvements have been made in the area of information technology, and devices do the measurements based on users' unique features. The data obtained can be checked and processed by using machine learning and Fuzzy methods. There are several sensors responsible for collecting health data from individuals, and these devices can be like smart watch or any device that comes with the person [11]. This can be used as the basis of the recommended system for people's health [12] One of the most basic philosophical foundations that have been supported so far is the use of Fuzzy sets in areas such as medicine, the various aspects of health as the concept of Fuzzy logic [13].

The problem with this study is that it identifies the factors affecting the adoption of mobile health services to expand this type of service, although this study faces many limitations, including the lack of a comprehensive mobile health system and its data. But this study hopes to identify potential areas in the field using the expertise of experts' who have studied the field. However, the main gap of this research is as follows: What is the impact of five main categories, including system quality, information quality, individual factors, service quality, and organizational quality on the acceptance of mobile health services, and to what extent? Five factors have been investigated in this research, each, in turn, has demonstrated their effectiveness with the Fuzzy AHP approach on mobile health service adoption.

The initial design of this study is to consider the use of the intended environment first, including experts who are familiar with mobile health acceptance and who have been associated with this issue. In this research, the most effective criteria were identified by the Fuzzy AHP method to help implement mobile health service adoption systems.

Finally, the results are evaluated positively and the factors are evaluated according to the hypotheses and the importance of the factors is described in the results. Moreover, the literature review mentions what the researchers know and what the researchers do not know in this field.

In this research, which is based on the fuzzy AHP method, we have been able to find the most effective, efficient, flexible and realistic factor based on the existing criteria by using the experts'.
This article is as follows: In the second part of the article, the literature review is discussed. The conceptual framework is provided in section 3. In Section 4, the research methodology is explained. In the fifth part, the results are presented. In Section 6, the discussion is explained. Finally, we concluded our study in Section 7 with the conclusion.

\section{LITERATURE REVIEW}

Although smart health is a new and emerging debate, it seems to have found its place in the modern world and its framework has been seriously raised. In addition, smart health has attracted special attention and not only helps people in the field of healthcare but also teaches them a smart way of living. According to Pramanik, Lau, Demirkan and Azad [1] Smart Health is a piece of the smart city puzzle.

The research believes that the components of the puzzle can be directly and indirectly affecting one another and ultimately influencing people in the community. In the following, a brief overview of the four issues of smart health, mobile health, Fuzzy sets in the context of mobile health, along with Fuzzy sets for health-related decision-making will be discussed.

\section{A. Smart Health}

Although the focus of this research is on mobile health using the Fuzzy AHP method, it is necessary to briefly discuss smart health, and then explain the mobile health and fuzzy sets on health.

Healthcare systems have come up with titles such as Mobile Health, Electronic Health, and Telemedicine to help medical science in order to create a professional and attractive environment and improve the quality of healthcare services. Hence, smart health has come with the slogan of removing place and time. Additionally, it looks for welfare in the community with the calculations intended to be smart [2]. Smart health is rooted in computer science and information technology, as well as a kind of business dealing with the Internet of Things. It also provides services for areas such as (insurance, medicine, and other related areas) to prevent diseases and improve patients' health. Meanwhile, there are sensors that receive data (breathing, body temperature, heart rate, etc.) from the patient and send it to the defined servers for analysis. Therefore, it can be argued that it is not only technology comes with health but smart health also helps to develop ICT to provide a true lifestyle for people in the modern world [3].

Figure 1 from Pramanik, Lau, Demirkan and Azad [1] states: "The state of health is a comprehensive healthcare and digital-classical healthcare, and ultimately, healthcare is a response and forms electronic health." In electronic health, medical records are recorded in Electronic Health Records (EHR) [4]. 


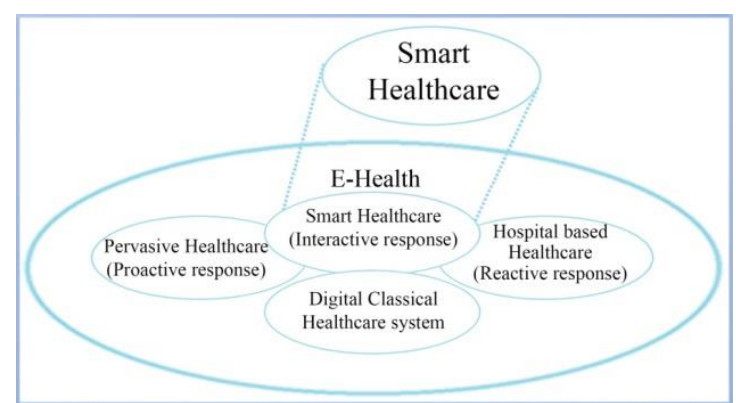

Fig.1. The Stages of the Emergence of Smart Health Components [1]

It should be stated that e-health benefits from EHR for storing information and for analyzing and processing health information [4]. The comprehensive healthcare system equipped with Local Area Network (LAN), and so on, works at a preventive level. Thus, health professionals are able to access the patient's information at any place with the device through the network $[5,6]$. The classic digital healthcare, which is a common practice in healthcare, was followed by physicians visiting patients after contact with them [7]. Hospital-based healthcare refers to those services that patients need to be referred to for treatment. It can be noted that EHR services, along with ICT tools, despite previous records, are used to improve the patient's condition better [8].

\section{B. Mobile Health}

Mobile health is rapidly expanding in the digital health sector, which provides healthcare support through mobile phone technologies such as smartphones. Mobile health is associated with all mobile devices and can transfer data to health centers and so forth. Mobile phones are currently the most popular platform for smart healthcare and treatment [9].

The term "Mobile Health" can be used to describe a wide range of healthcare activities in both clinical and non-clinical populations. For example, there are diverse, popular applications of smart healthcare that help people improve and monitor their fitness. However, recent researches have indicated that many of these applications, including clinical and non-clinical health technologies, do not fully comply with clinical guidelines [10]. There is a major health problem for this industry and it is how to improve the quality of technology to combine scientific documentation [11].

Nevertheless, mobile health technology is used as a powerful medical tool to support the provision of healthcare at all levels. For example, GP Skype on mobile phones and wireless blood pressure and glucose monitoring connected to the user's phone is sent automatically to the user's physician. One of the important benefits of mobile health is to potentially provide interpersonal, interactive, and health-compatible interventions in everyday life, and overcome many of the traditional health-related barriers, such as time and resources. Currently, hospitals conduct their goals with ICT-based health systems as a means to improve the quality, safety and efficiency of health services. In EHealth, medical professionals and business owners in this field connect through related technologies, such as the Internet. Mobile health technology provided by hospitals and health systems under ICT in the 1990s. A key element in health systems is the emergence of EHR, or ehealth records, also enabled personal health records (EHRs). Usually, healthcare providers keep patient records. However, it is common for patients to have access to these data and, on the other hand, have concerns about privacy [12]. An EHR system is basically a repository of information about a patient's health file in a computerized form [13]. Establishing an EHR system can bring many benefits to a public health system. For example, more efficient and lower management costs, effective management and high-volume patient information and patient records will be concentrated [14]. Mobile health systems and its mobility capabilities have important implications for monitoring healthcare systems and warning systems such as clinical and administrative data collection, patient information storage and maintenance, healthcare delivery plans, medical information, diagnosis and prevention systems, drug abuse and so on [15]. The mobile health architecture is presented in Figure 2, which uses Internet and Web services to provide valid and comprehensive interaction between doctors and patients. A physician or patient can easily access an EHR through their PC or smartphone at anytime, anywhere. In emergency cases, the patient can contact the doctor or even have a doctor's appointment or medical appointment, regardless of time and place [16]. Medical data are generated differently way from the past Li, Land, Chattopadhyay and Ray [12] and, on the other hand, it requires an efficient and accurate solution for new technology in the world of technology [17].

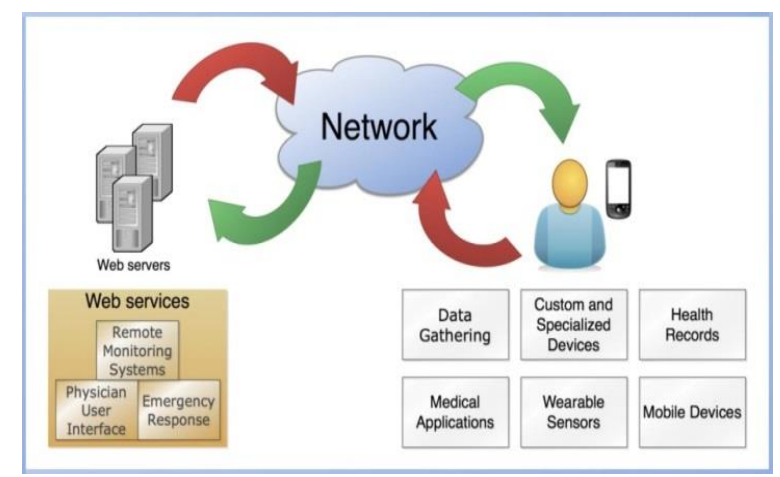

Fig.2. Illustration of Mobile Health Architecture [16].

Fig.2 illustrates the overall architecture and mobile health framework, which is actually a network connected to patient databases and information, and the other one connected to the patient himself to obtain patient information and data through mobile devices. This illustrates a comprehensive review of mobile health architecture, healthcare issues, and mobile health applications. Moreover, it presents one of the most important depth analysis researches of new and available health and treatment services.

Fiordelli, Diviani and Schulz [18] examined mobile health researches from 2002 to 2012 in order to 
investigate the impact of mobile phones. They acknowledged that they did not consider the articles from the technology databases; rather they looked at numerous mobile health programs in software stores associated with a lack of systematic research.

Handayani, Meigasari, Pinem, Hidayanto and Ayuningtyas [19] studied ease of use and quality dimensions in the system, as well as assured support in organizational dimensions. Health centers management and health service providers were also required to offer their full support in this area over the long term. Therefore, healthcare services should be user-friendly to be widely distributed and accepted by the vast majority of patients.

\section{Fuzzy Sets in the Mobile Health Context}

In this section, a brief description of the literature on the use of Fuzzy logic in mobile health is presented. Additionally, this paper suggests that key factors to mobile health using Fuzzy AHP from academic experts to be weighted and analyzed since professors in the Information Technology (IT) and computer group, as well as the Health Information Management Group, are the closest connected generation to mobile health technology and its new developments. Although research in this field has not been widely accepted yet, several examples of fuzzy logic applications in the field of health are presented.

There are potential advantages of Fuzzy optimization tools that can consider uncertainty in the design of advisory systems. As Mezei and Nikou [20] have identified a new pathway for the youth and elderly to search and use health-related data in health-promoting systems. They also noted the necessity of using the strong ICT platform in order to achieve a favorable outcome in the field of mobile health.

However, one cannot ignore the effective role of the tablet, smartphone, smart watch, smart bracelet and other wearable devices in speeding up mobile health services. In general, it can be argued that these smart devices monitor human behavior. Fuzzy logic has been mentioned as an advantage in solving difficult and complex problems in mobile health and personal health monitoring. It is also used to achieve a clear insight into such issues [21].

For example, the fuzzy case-based reasoning (CBR) system has been presented by the decision support system for diabetes. This system accelerates the diagnostic process and also provides a fuzzy semantic algorithm [22]. A Fuzzy optimization approach for advisory systems is provided by Mezei and Nikou [23] that examines the decision to optimize user's health conditions from different perspectives. A model for increasing some health decisions is also recommended. This approach is used in wellness programs and it brings the best possible mode to a user's specific situation. The main purpose of the study was to use the Fuzzy optimal model in a health-related decision-making model.

\section{Fuzzy sets for mobile health decision-making}

One of the main application areas of fuzzy logic and fuzzy set theory concerns decision-making problems in the presence of imprecise or vague information [20]. The research intends to use the Fuzzy AHP method to solve such problems. In addition, oral evaluations provided by the expert in this field can be considered as key uses of fuzzy sets in decision-making. Moreover, medical or health decision-making problems are some of the instances of this phenomenon. There is also a fuzzy expert system to diagnose pulmonary diseases and medical diagnosis [24]. The efficiency and integrity of the fuzzy rule system has been accentuated in another study, which is based on fuzzy logic to predict the risk of heart disease. Furthermore, a healthcare system for cardiovascular disease is considered by the data mining method [25]. It is also necessary to mention approaches such as fuzzy clustering Chuang, Tzeng, Chen, Wu and Chen [26] or semantic classification Nauck and Kruse [27]. In particular, a fuzzy set has been considered at multiple intervals and widely used in healthcare problems. Another approach to fuzzy decision-making systems for wellness solutions as well as elderly healthcare is [28] for the daily activities of the youth and elderly group. A program that is already under a planned system and predetermined activities helps the health of this group despite signs and warnings. They also programmed fuzzy logic to measure the rate of wasted activity.

\section{CONCEPTUAL FRAMEWORK}

This research looks for a strategy for the proper adoption of health technology in order to realize the continuous and optimal use of this new technology. The adoption of this technology by the user is expected to include the five main criteria of the factors. These criteria include the quality of the system, the quality of the information, the individual factors, the quality of the services and the organizational factors, the sub-criteria of each of which are clearly indicated in figure 4 .

However, this article seeks to weigh the key factors of mobile health acceptance using the Fuzzy AHP method from experts in higher education. Such an analysis, in the field of health with the Fuzzy AHP approach, has not been carried out so far in the Faculty of Engineering of Islamic Azad University, South Tehran Branch. This research uses a quantitative approach.

It can be stated that AHP is a Multiple-Criteria Decision Analysis (MCDA) that uses some mathematical methods to transform mental judgments and qualitative data into quantitative data, and the fuzzy method is used to convey vague and unspecified information [29].

At first, the prototype was selected by eight professors from Information Technology (all sub-disciplines), Computer Engineering (all sub-disciplines), and the Department of Health Information Management from several universities and they were interviewed. 
After collecting and eliminating defects and extracting the Consistency Ratio (CR), which was less than 0.1 or equal 0.1 , the questionnaires were distributed widely among faculty members. In the end, 21 questionnaires were collected, the results were analyzed, and 19 of them were used.
The research model is derived from "Handayani, Meigasari, Pinem, Hidayanto and Ayuningtyas [19]" and "Jeon and Park [30]". Figure 3, Handayani, Meigasari, Pinem, Hidayanto and Ayuningtyas [19] research model, illustrates the successful factors for implementing mobile health in Indonesia.

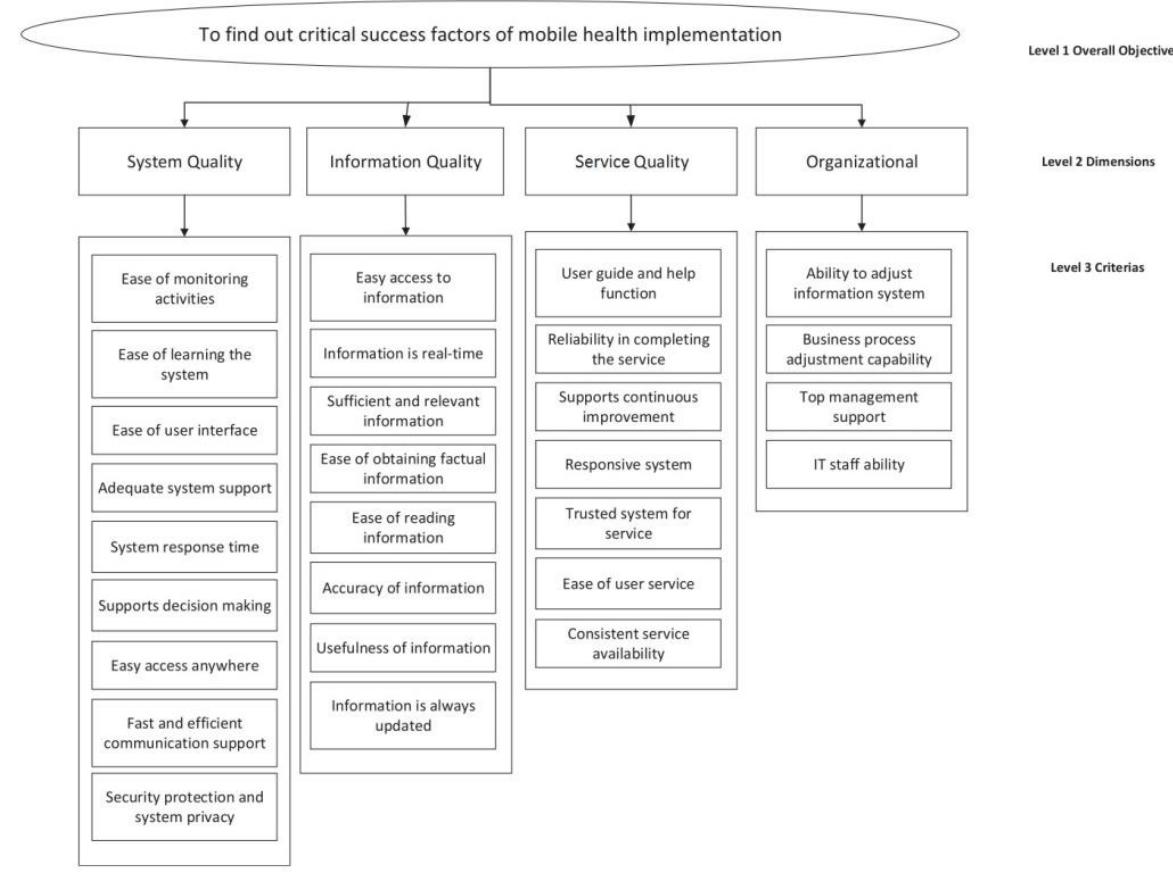

Fig.3. Essential and Successful Factors for Mobile Health Implementation [19].

Handayani, Meigasari, Pinem, Hidayanto and Ayuningtyas [19] includes four major criteria, such as system quality, quality of information, service quality, and organizational factors. After surveys, and based on the previous studies, some of the factors in Figure 3 are used for this article. The study believes that the implementation of a successful mobile health system should be user-friendly along with their satisfaction.

In this model, some factors of Jeon and Park [30] taken from TAM2 as a measure of individual factors were used. In the TAM model, four main factors come together including Compatibility, Perceived Usefulness (PU) and Perceived Ease of Use (PEOU) and Behavioral Thinking (BI), and developed the Technology Acceptance Model (TAM2).

The figure above illustrates some important criteria to implement mobile health admission system as all the criteria in this figure are in line with the research [19]. In the methodology, the target population includes experts from some Iranian universities. Therefore, this study selected the criteria based on the two studies [19] and [30] as illustrated in (Fig. 4). In Table 1, all the criteria used in this study are fully introduced and evaluated.

This research aims to develop a model of effective factors to accept mobile health technology in which users' privacy issue is considered, the accuracy of information is high in order to stabilize the individual's compatibility with this system. In this case, trust to use the service goes up. It is obvious that this requires the support of an excellent management.

Therefore, system quality, information quality, individual factors, service quality, and organizational factors are combined, which leads to the following hypotheses:

\section{A. System Quality}

In spite of extensive research on smart health, much research and study is still need to be carried out for the effectiveness of this technology in terms of quality in system decision making that leads to patient satisfaction, reduced time and cost for patients and treatment centers. Some of the indicators of quality system are data processing range, access limits, transport capability (access to this technology at any time/place), and communication quality [31]. having the following subcriteria including ease of learning the system, system response time, easy access anywhere, fast and efficient communication support, security protection and system privacy, the following hypothesis is formed:

H1: From the experts' view, the quality of the mobile health system has a direct impact on the adoption of mobile health technology.

\section{B. Information Quality}

The health issue deals with the lives of humans, and even the low percentage of errors here is high and unacceptable. There are many factors together that enhance information quality, and if there is a problem 
with one of these cases, it also has a negative impact on other factors. One of the key mobile health missions is to provide medical or patient information in real time. The accuracy of information is of paramount importance. Information quality points out that to implement a successful mobile health system, information should be easily accessible and up-to-dated [31]. In order that mobile health technology can play an important role in health-related decisions, it should prepare the ground for accurate, real-time information. Hence, the patient and the physician should be able to access this information at any time and place [32]. Information quality is an integral part of mobile health acceptance. In this research, the criterion of information quality has the following subcriteria: easy access to information, real-time information, sufficient and relevant information, accuracy of information, and Information is always Updated. Thus, $\mathrm{H} 2$ is formed:

H2: From experts' view, Information quality in mobile health has a direct impact on the acceptance of mobile health technology.

\section{Individual Factors}

The individual behavior and attitude to mobile health services system are also important factors in improving mobile health process. Compeau and Higgins [33] have enumerated the individual factors and the user's proper understanding of a particular technology as the inseparable nature of that system. On the other hand, the type of individual's attitude to mobile health system and one's understanding of the system have a significant impact on the adoption of Internet-based health services. Privacy and trust are the issues that influence individual behavior [30]. Acceptance of mobile health technology depends on individual factors and compatibility to the health system, as a correct understanding of the use of this technology leads to improved system performance. However, individual factors have the following subcriteria: compatibility, perceived usefulness, perceived ease of use, and behavioral intend to use. Thus, H3 is formed:

H3. From experts' view, Individual factors in mobile health have a direct impact on the adoption of mobile health technology.

\section{Service Quality}

There are different algorithms that lead to the acceptance of services and products in the mobile health sector. Among them, the TAM model can be used to provide theories for the acceptance of mobile health services [34]. Smartphones, on the other hand, are one of the most widely used devices for accessing mobile health services, as they offer ease of use, and availability of services. Since smartphone is a personal device, the user trusts in putting one's health information [31]. However, the underlying service quality factors are linked to the performance of smartphones in the healthcare sector. Health services have also been able to establish close links between patients, physicians and healthcare providers and add to their capabilities [35, 36]. According to the Delone and McLean [37] model, it can be inferred that service quality affects the level of customer satisfaction in the health sector. Finally, the standard of service quality for sustainability of mobile healthcare services is very evident along with the sub-criteria of responsive system, trusted system for service, ease of user service, consistent service availability form $\mathrm{H} 4$ :

H4: From experts' view, the quality of health services has a direct impact on the acceptance of healthcare technology.

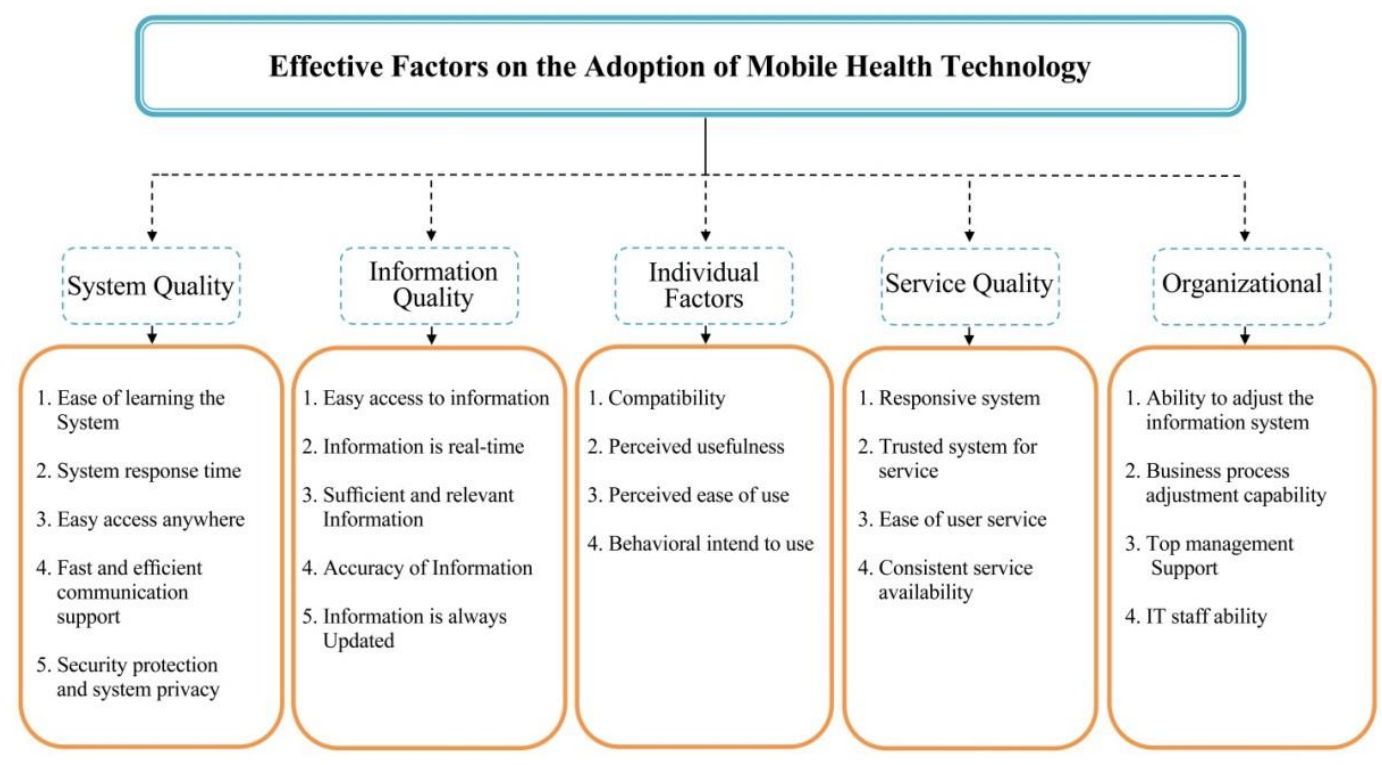

Fig.4. Proposed Model of Effective Factors on the Adoption of Mobile Health Technology. 


\section{E. Organizational}

Organizational factors play an important role in the adoption of technology-based mobile healthcare services. Having an integrated information system as well as setting up a desirable business process can be enumerated. Handayani, Meigasari, Pinem, Hidayanto and Ayuningtyas [19] highlighted the support of excellent management as an influential factor in the acceptance of mobile health technology. Studies show that IT can be effective in shaping organizational strategies Buhalis [38] because it can be beneficial for organizations in terms of time and cost [39]. In this research, it is assumed that the criterion of organizational factors influence on the adoption of mobile health by considering the following sub-criteria of ability to adjust the information system, business process adjustment capability, top management support, and IT staff ability. Thus, H5 is formed:

H5: From experts' view, organizational factors in mobile health have a direct impact on the adoption of mobile health technology.

Table 1. Determination of key factors in the questionnaire and definitions.

\begin{tabular}{|c|c|c|c|}
\hline Dimension & $\begin{array}{l}\text { Criteria's } \\
\text { Code }\end{array}$ & Criteria & Description \\
\hline \multirow[t]{5}{*}{ System Quality (SYQ) } & SYQ1 & $\begin{array}{l}\text { Ease of learning the } \\
\text { System }\end{array}$ & $\begin{array}{l}\text { Whether learning from mobile health systems is easy for new users or not [40, } \\
41]\end{array}$ \\
\hline & SYQ2 & System response time & $\begin{array}{l}\text { The response time by the system that the user intends to take advantage of } \\
{[40,41] \text {. }}\end{array}$ \\
\hline & SYQ3 & $\begin{array}{l}\text { Easy access } \\
\text { anywhere }\end{array}$ & $\begin{array}{l}\text { The ability to integrate data so that the user can access its data at any time and } \\
\text { place }[42,43] \text {. }\end{array}$ \\
\hline & SYQ4 & $\begin{array}{l}\text { Fast and efficient } \\
\text { communication } \\
\text { support }\end{array}$ & $\begin{array}{l}\text { The system's ability for mutual support of effective and efficient } \\
\text { communication in the field of health [40]. }\end{array}$ \\
\hline & SYQ5 & $\begin{array}{l}\text { Security protection } \\
\text { and system privacy }\end{array}$ & $\begin{array}{l}\text { Unauthorized use or use of the system by unauthorized persons is not within } \\
\text { the scope of protection of privacy and security [42]. }\end{array}$ \\
\hline \multirow[t]{5}{*}{$\begin{array}{l}\text { Information Quality } \\
\text { (INQ) }\end{array}$} & INQ1 & $\begin{array}{l}\text { Easy access to } \\
\text { information }\end{array}$ & $\begin{array}{l}\text { It is easy to access information by using some mobile devices, and the need } \\
\text { for direct access to information is recommended to improve performance [ } 40 \text { - } \\
43] \text {. }\end{array}$ \\
\hline & INQ2 & $\begin{array}{l}\text { Information is real- } \\
\text { time }\end{array}$ & $\begin{array}{l}\text { If healthcare information is timely provided, the risk of many diseases is } \\
\text { eliminated and more favorable decisions can be made [44]. }\end{array}$ \\
\hline & INQ3 & $\begin{array}{l}\text { Sufficient and } \\
\text { relevant } \\
\text { Information }\end{array}$ & $\begin{array}{l}\text { To improve technology in an organization or company, there is a } \\
\text { technological capability so that users can obtain information from the } \\
\text { databases in that company }[40,42-44] \text {. }\end{array}$ \\
\hline & INQ4 & $\begin{array}{l}\text { Accuracy of } \\
\text { Information }\end{array}$ & $\begin{array}{l}\text { Error in the field of health has no place and hence precision is one of the most } \\
\text { important topics of information quality since the patient's health depends on } \\
\text { the same amount of error [40]. }\end{array}$ \\
\hline & INQ5 & $\begin{array}{l}\text { Information is always } \\
\text { Updated }\end{array}$ & $\begin{array}{l}\text { The result of the research suggests that user satisfaction depends on updating } \\
\text { the system by the IT sector [41]. }\end{array}$ \\
\hline \multirow[t]{4}{*}{$\begin{array}{l}\text { Individual } \\
\text { Factors(INF) }\end{array}$} & INF1 & Compatibility & $\begin{array}{l}\text { Individual compatibility with the health system, as well as the flexibility of } \\
\text { the system for a variety of users [45] }\end{array}$ \\
\hline & INF2 & Perceived usefulness & $\begin{array}{l}\text { Wu, Wang and Lin [34] integrated the MHS acceptance model with perceived } \\
\text { benefits of PU, which significantly contributed to the goal of professional } \\
\text { healthcare interventions. }\end{array}$ \\
\hline & INF3 & Perceived ease of use & $\begin{array}{l}\text { Wu, Wang and Lin [34] concluded in their model that the MHS model had a } \\
\text { direct impact on healthcare behavior through the ease of perception variable. }\end{array}$ \\
\hline & INF4 & $\begin{array}{l}\text { Behavioral intend to } \\
\text { use }\end{array}$ & $\begin{array}{l}\text { In the adoption of mobile healthcare system model, Jeon and Park [30] control } \\
\text { the behavior of users and users of mobile health systems to improve the } \\
\text { performance of this system. }\end{array}$ \\
\hline \multirow[t]{4}{*}{ Service Quality (SEQ) } & SEQ1 & Responsive system & $\begin{array}{l}\text { Regarding successful implementations and improved responsiveness to the } \\
\text { user, system responsiveness can reduce a significant amount of error [44]. }\end{array}$ \\
\hline & SEQ2 & $\begin{array}{l}\text { Trusted system for } \\
\quad \text { Service }\end{array}$ & $\begin{array}{l}\text { Users' trust in the smart healthcare system is not gained unless they are } \\
\text { proven credible, and they are assured of the convenience, efficiency and } \\
\text { security of the system [40]. }\end{array}$ \\
\hline & SEQ3 & Ease of user service & $\begin{array}{l}\text { In order to improve the quality of services, systems need to create new } \\
\text { opportunities and take steps to improve the status of users [44]. }\end{array}$ \\
\hline & SEQ4 & $\begin{array}{l}\text { Consistent service } \\
\text { availability }\end{array}$ & $\begin{array}{l}\text { If access to services is easily provided, users' satisfaction also increases, and } \\
\text { treatment process will face fewer problems [43]. }\end{array}$ \\
\hline \multirow[t]{4}{*}{ Organizational (ORG) } & ORG1 & $\begin{array}{l}\text { Ability to adjust the } \\
\text { information system }\end{array}$ & $\begin{array}{l}\text { Information system setup capabilities can provide some applications for users, } \\
\text { and this is also important for the needs of the medical group and other areas } \\
{[42,46] \text {. }}\end{array}$ \\
\hline & ORG2 & $\begin{array}{l}\text { Business process } \\
\text { adjustment capability }\end{array}$ & $\begin{array}{l}\text { From another perspective, health is a type of business, and the organization } \\
\text { must have the ability to adapt the processes of the mobile health system and } \\
\text { the business by granting facility in this area }[46,47] \text {. }\end{array}$ \\
\hline & ORG3 & $\begin{array}{l}\text { Top management } \\
\text { Support }\end{array}$ & $\begin{array}{l}\text { The development of organizational projects has a particular strategy that } \\
\text { requires the support of excellent management. This does not exclude the } \\
\text { development of a mobile health system }[42,46,47] \text {. }\end{array}$ \\
\hline & ORG4 & IT staff ability & $\begin{array}{l}\text { To have a successful health system in the context of IT, organization needs to } \\
\text { have an experienced IT team with a high level of analytical expertise [42, 46, } \\
\text { 47]. }\end{array}$ \\
\hline
\end{tabular}




\section{RESEARCH METHODOLOGY}

In the field of information technology, random models improve the motivation and development due to the ability to describe and analyze the theoretical relationship between variables. On the other hand, Meng, Guo, Peng, Zhang and Vogel [48] believes that by raising the quality level of mobile health system, the continued use of these services increases by citizens. They also emphasized the importance of informing citizens about the issues of health and mobile health services. Fuzzy AHP is used for multi-criteria decision making for the Fuzzy AHP pairwise comparison matrix (PCM). The weight of the variables is extracted in AHP and the variables are weighed and ranked, in this case, the desirable MCDM can be seen. This research is based on the main criteria as well as the following criteria, as presented in Table 1. Moreover, the specifications of experts are described in Table 3.

\section{A. Fuzzy Analytic Hierarchical Process (FAHP)}

One of the most commonly used multi-criteria decision-making methods is the AHP method proposed by Mr. Saaty [49]. In fact, complex issues are analyzed in a hierarchy. The growing number of MCDM decisions by researchers from Fuzzy AHP has transformed this approach into one of the most popular methods for multicriteria decision-making [50, 51].

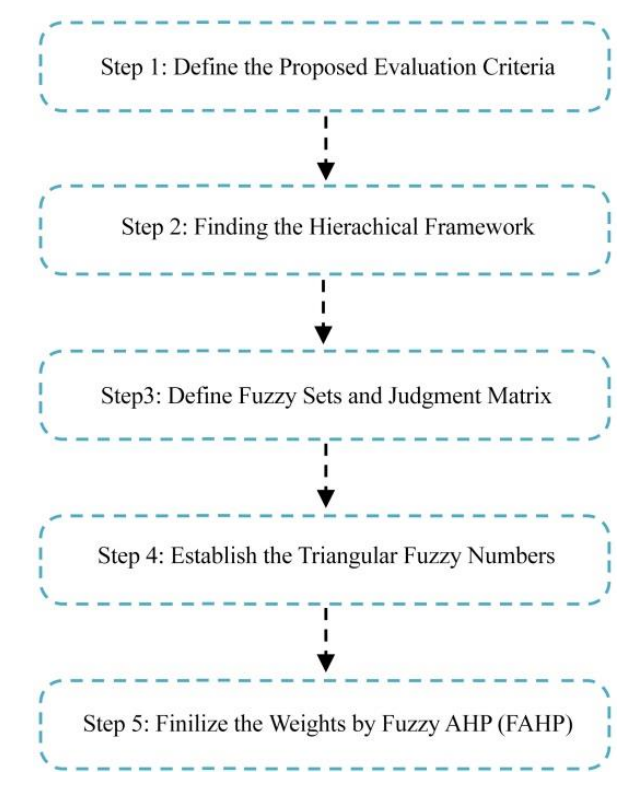

Fig.5. Evaluation framework for essential factors [52].

In a fuzzy set, the membership function proposes to the ratio of a fuzzy number by the decision maker. The membership function also introduces the variables in the judgment levels that belong to the prioritization set [51].
In this paper, Fuzzy AHP method is used for weighting the variables and sub variables for the adoption of mobile health technology. It can be argued that Fuzzy AHP is an extension of the classical AHP methodology, which considered the decision maker's fuzziness [53]. It should also be added that Fuzzy AHP is a constructive approach to multi-criteria decision making (MCDM) in a fuzzy context and it is a precise analysis prediction method [54].

\section{B. Fuzzy Logic and Fuzzy Set}

Fuzzy numbers are separate classes of fuzzy values, and the fuzzy value here is represented by $\mathbf{M}$, which indicates the integer of a number $r$ as a real number. Here, $\mathrm{m}(\mathrm{x})$ must be measured so that $\mathrm{m}(\mathrm{x})$ approaches the "r". A normal fuzzy set denotes the fuzzy number of $f$. If the interval is given in real numbers, it is specified by degrees between 0 and 1 .

$$
\mu(x / M)=\left\{\begin{array}{l}
0, \quad x<1 \\
\frac{x-a}{b-a} \quad a x x \\
\frac{c-x}{c-b} b \\
0, \quad x>u
\end{array}\right.
$$

The number of fuzzy numbers that can be used varies according to research conditions, but usually Triangular Fuzzy Numbers (TFNs) and trapezoidal are commonly used [52]. Utilizing TFNs makes it easy to work in programs since it is computationally simple. Similarly, it seems more appropriate to work on information processing in a fuzzy environment $[55,56]$.

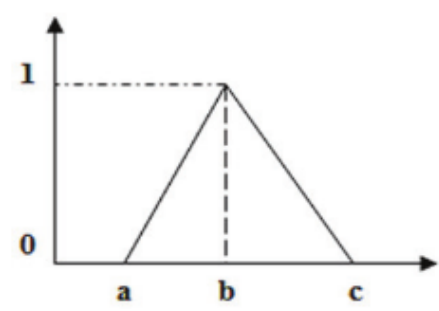

Fig.6. Represents a triangular fuzzy, M.

The letters a, b, c shown in Fig. 6 are also defined in TFNs and represent three real numbers. These parameters, which define the fuzzy event, mean the smallest possible and most hopeful and also the largest amount [52].

Table 2 describes the relative importance scale used in the paired comparison matrix. It also describes the verbal expressions of importance five-point Likert scale including exactly equal, weakly important, strongly more important, very strongly important, and absolutely high importance. 
Table 2. Scale of relative importance used in the pairwise comparison matrix.

\begin{tabular}{cccc}
\hline Row & Triangular Fuzzy Numbers & Triangular & Linguistic Term \\
\hline 1 & $(1,1,1)$ & $(1,1,1)$ & Exactly Equal \\
2 & $(1,3,5)$ & $(1 / 5,1 / 3,1)$ & Weakly Important \\
3 & $(3,5,7)$ & $(1 / 7,1 / 5,1 / 3)$ & Strongly More Important \\
4 & $(5,7,9)$ & $(1 / 9,1 / 7,1 / 5)$ & Very Strongly Important \\
5 & $(7,9,11)$ & $(1 / 11,1 / 9,1 / 7)$ & Absolutely High Importance \\
\hline
\end{tabular}

In this table, the triangular fuzzy of five-point Likert scale is also included.

\section{Data Collection and Analysis}

This study aims to find effective factors on the adoption of mobile health by using an expert-level questionnaire and among faculty members of computer science, information technology, and health information management. Experts of these departments were interviewed since they were more aware of the growth of technologies, especially health, under information technology. In this research, after a thorough review, some of the main and influential factors, as well as its underlying factors (Table 1), were extracted. With respect to the quantitative approach, an online E-mail questionnaire, based on AHP- pair comparison between the factors, including a five-point Likert scale (Table 2), was developed. It was sent through academic email and several online scientific associations for some faculty members of the domestic universities such as Islamic Azad University-South Tehran Branch, University of Tehran, Amirkabir University of Technology, Islamic Azad University-Science and Research Branch of Tehran, Shahid Beheshti University, Islamic Azad University of Qazvin Branch, Isfahan University of Medical Sciences, and one foreign university; University Technology of Malaysia.

On the other hand, an initial assessment to obtain the accuracy of the questionnaire was done after completing 8 questionnaires by the experts. The AHP computation results were matched to both the Consistency Index (CI) and Consistency Ratio (CR) indicators, both of which were less than or equal to 0.1 (suggested by Saaty). Table 3 represents the experts' profile. The youngest person was 32, and the oldest one was 66.

Table 3. The interview experts' background.

\begin{tabular}{|c|c|c|c|c|c|}
\hline No. & Gender & Age & Marital status & Experts' academic rank & Field of study \\
\hline 1 & Male & $32-44$ & Married & Assistant professor & Information Technology \\
\hline 2 & Male & $32-44$ & Married & Associate professor & Information Technology \\
\hline 3 & Female & $32-44$ & Single & Assistant professor & Information Technology \\
\hline 4 & Male & $32-44$ & Married & Associate professor & Computer Science \\
\hline 5 & Female & $32-44$ & Married & Associate professor & Information Technology \\
\hline 6 & Female & $32-44$ & Married & Assistant professor & Information Technology \\
\hline 7 & Female & $32-44$ & Married & Assistant professor & Information Technology \\
\hline 8 & Male & $45-64$ & Bachelor & Assistant professor & Computer Science \\
\hline $9^{x}$ & Male & $32-44$ & Married & Assistant professor & Health Information Management \\
\hline 10 & Male & $45-64$ & Married & Full professor & Computer Science \\
\hline 11 & Female & $32-44$ & Single & Assistant professor & Information Technology \\
\hline 12 & Female & $32-44$ & Single & Instructress & Computer Science \\
\hline 13 & Female & $32-44$ & Married & Instructress & Information Technology \\
\hline 14 & Female & $45-64$ & Single & Full professor & Health Information Management \\
\hline 15 & Male & $32-44$ & Bachelor & Associate professor & Health Information Management \\
\hline 16 & Male & $45-64$ & Married & Associate professor & Computer Science \\
\hline 17 & Male & $32-44$ & Married & Assistant professor & Information Technology \\
\hline 18 & Male & $45-64$ & Married & Full professor & Health Information Management \\
\hline $19^{x}$ & Female & $45-64$ & Single & Associate professor & Computer Science \\
\hline 20 & Female & $32-44$ & Single & Assistant professor & Computer Science \\
\hline 21 & Male & $>65$ & Married & Full professor & Computer Science \\
\hline
\end{tabular}

${ }^{\bar{x}}$ Refers to those who refused to revise and correct questionnaire responses.

It should be noted that the sample of the questionnaire completed by the experts in the early stages is available in Appendix (A). The interview process was also conducted in the summer of 2019. However, 21 experts were interviewed online and in person. After the evaluations, some of the responses needed to be corrected by them and 2 of them refused for personal reasons. The data was processed using Fuzzy AHP, which can solve the problems of uncertainty and mental decision-making problems. This approach is a type of decision-making method that can determine the weight of a data group. The analysis of these criteria is characterized by the highest value variations and the highest valuation.

One of the innovations of this research is that before 
the experts wanted to answer 48 questions (Appendix A), their interest in mobile health was examined by asking them two questions.

1. If the mobile health system is to be comprehensive, which of mobile health applications will attract your attention?

2. If the mobile health system is to be comprehensive, how many times do you use mobile health services during the week?

Table 4. The study of the experts' interest in mobile health applications

\begin{tabular}{|c|c|c|c|}
\hline $\mathbf{Q}$ & Options & Frequency & (Percent) \\
\hline \multirow[t]{4}{*}{ Q1 } & $\begin{array}{l}\text { 1. The mobile health that the health information of the person is already provided to the mobile health } \\
\text { software on the mobile phone and the software give medical orders and instructions. }\end{array}$ & 2 & $10.5 \%$ \\
\hline & $\begin{array}{l}\text { 2. Mobile health based on smart devices such as smart watch or smart bracelet that sends your health status } \\
\text { online to the mobile phone app and informs you or your doctor or medical centers about its analysis. }\end{array}$ & 15 & $78.9 \%$ \\
\hline & $\begin{array}{l}\text { 3. According to the medical information that is already available, medical advice will be sent via SMS to } \\
\text { your mobile phone. }\end{array}$ & 1 & $5.3 \%$ \\
\hline & 4. Other cases. & 1 & $5.3 \%$ \\
\hline \multirow[t]{4}{*}{ Q2 } & 1. Almost every day. & 11 & $57.9 \%$ \\
\hline & 2. Almost less than 7 times a week. & 5 & $26.3 \%$ \\
\hline & 3. I will rarely use this technology. & 2 & $10.5 \%$ \\
\hline & 4. I may not use it. & 1 & $5.3 \%$ \\
\hline
\end{tabular}

Ultimately, the experts' response to both questions was that the majority agreed with the pervasiveness of this issue and emphasized the need to use this technology during the week. In response to the first question, which $78.9 \%$ selected the second option, it can be inferred that the convenience of service combined with system quality and, of course, responding in real-time to users of this technology is a priority. In the second question, which the majority has chosen the daily/weekly use of this technology, shows the adoption of this technology. However, it should be noted that people across the world do not care about the health issue as much as they should. The study believes that by touching on the mobile health technology and the pervasiveness of those thoughts and answers, it can be different.

\section{RESULTS}

\section{A. Comparing and evaluating the main factors}

By using the online AHP questionnaire, this study evaluates the effective variables on the adoption of mobile health as well as their importance. In this ranking, the relative importance of the effective factors on the adoption of mobile health is presented. The results of this ranking can be a roadmap for future researchers.

Table 5. AHP weights and the ranking levels of main and sub factors.

\begin{tabular}{|c|c|c|c|c|c|}
\hline Main Factors & Weight (w) & Ranking & Sub- Factors & Weight (w) & Ranking \\
\hline \multirow{5}{*}{ System Quality (SYQ) } & \multirow{5}{*}{0.24} & \multirow{5}{*}{1} & Ease of learning the system & 0.18 & 3 \\
\hline & & & System response time & 0.16 & 4 \\
\hline & & & Easy access anywhere & 0.19 & 2 \\
\hline & & & Fast and efficient communication support & 0.14 & 5 \\
\hline & & & Security protection and system privacy & 0.31 & 1 \\
\hline \multirow{5}{*}{ Information Quality (INQ) } & \multirow{5}{*}{0.22} & \multirow{5}{*}{2} & Easy access to information & 0.13 & 5 \\
\hline & & & $\begin{array}{l}\text { Information is real-time } \\
\text { Sufficient and relevant }\end{array}$ & 0.17 & 4 \\
\hline & & & $\begin{array}{l}\text { Sufficient and relevant } \\
\text { information }\end{array}$ & 0.19 & 3 \\
\hline & & & $\begin{array}{l}\text { Intormation } \\
\text { Accuracy of information }\end{array}$ & 0.23 & 2 \\
\hline & & & Information is always updated & 0.25 & 1 \\
\hline \multirow{5}{*}{ Individual Factors(INF) } & \multirow{5}{*}{0.21} & \multirow{5}{*}{3} & Compatibility & 0.25 & 3 \\
\hline & & & Perceived usefulness & 0.26 & 2 \\
\hline & & & Perceived ease of use & 0.29 & 1 \\
\hline & & & Behavioral intend to use & 0.21 & 4 \\
\hline & & & Responsive system & 0.22 & 2 \\
\hline \multirow{3}{*}{ Service Quality (SEQ) } & \multirow{3}{*}{0.18} & \multirow{3}{*}{4} & Trusted system for service & 0.39 & 1 \\
\hline & & & Ease of user service & 0.18 & 4 \\
\hline & & & Consistent service availability & 0.19 & 3 \\
\hline \multirow{4}{*}{ Organizational (ORG) } & \multirow{4}{*}{0.15} & \multirow{4}{*}{5} & Ability to adjust the information system & 0.25 & 2 \\
\hline & & & Business process adjustment capability & 0.19 & 4 \\
\hline & & & Top management support & 0.32 & 1 \\
\hline & & & IT staff ability & 0.22 & 3 \\
\hline
\end{tabular}

The rating of the main factors from the most important to the least important is as follows:

System Quality (SYQ) (w=0.24), Information Quality
(INQ) (w=0.22), Individual Factors (INF) $(\mathrm{w}=0.21)$, Service Quality (SEQ) ( $\mathrm{w}=0.18)$, Organizational $(\mathrm{ORG})$ $(\mathrm{w}=0.15)$. 
In this research, accepting or rejecting hypotheses, as in [57], is as follows. In general, based on the above results, and from the experts' point of view, the main criterion is "System Quality (SYQ)" ( $w=0.24)$ with the highest weight and it is the most effective factor for mobile health adoption. Then, two criteria of "Information Quality (INQ)" (w = 0.22), and "Individual Factors (INF)" ( $\mathrm{w}=0.21)$ are more important than "Service Quality (SEQ)" ( $\mathrm{w}=0.18)$, and "Organizational $(\mathrm{ORG}) "(\mathrm{w}=0.15)$. The computational results were matched to both the Consistency Index (CI) and Consistency Ratio (CR) indicators, both of which were less than or equal to 0.1 (suggested by Saaty).

For tangible factors, if experts are involved in the implementation of mobile health technology in the industrial environment, first, they should consider the main factors (SYQ), (INQ), (INF) and then examine the two factors (SEQ) (ORG) in the following cases. For some mathematical operations, scales should be converted to a fuzzy scale. Generally, different types of fuzzy scales can be used. In this study, the triangular fuzzy transformation scale of the Gumus [58] model has been used.

Table 6. Possibility for a convex fuzzy number.

\begin{tabular}{ccccccccccccc}
\hline SYQ & $\mathbf{1 2 . 1 4 0}$ & $\mathbf{1 8 . 2 0 0}$ & $\mathbf{2 4 . 3 3 0}$ & $*$ & $\mathbf{0 . 0 1 3}$ & $\mathbf{0 . 0 1 9}$ & $\mathbf{0 . 0 3 1}$ & $\mathbf{0 . 1 5 9}$ & $\mathbf{0 . 3 4 1}$ & $\mathbf{0 . 7 4 7}$ \\
\hline INQ & 8.140 & 14.200 & 20.330 & $*$ & 0.013 & 0.019 & 0.031 & $=$ & 0.107 & 0.266 & 0.625 \\
INF & 6.140 & 12.200 & 18.330 & $*$ & 0.013 & 0.019 & 0.031 & $=$ & 0.081 & 0.229 & 0.563 \\
SEQ & 4.480 & 6.730 & 9.660 & $*$ & 0.013 & 0.019 & 0.031 & $=$ & 0.059 & 0.126 & 0.297 \\
ORG & 1.650 & 2.000 & 3.530 & $*$ & 0.013 & 0.019 & 0.031 & $=$ & 0.022 & 0.038 & 0.108 \\
\hline
\end{tabular}

\section{B. Comparison and assessment of sub-criteria}

\section{- $\quad$ System Quality (SYQ)}

In this study, system quality plays the most important role in admitting mobile health technology. The subfactors of system quality that have been examined and evaluated are as follows:

Ease of learning the system (SYQ1)", "System response time (SYQ2)", "Easy access anywhere (SYQ3)", "Fast and efficient communication support (SYQ4)", "Security protection and system privacy "(SYQ5).

The following five sub-factors below are the most important to the least one:

"Security protection and system privacy (SYQ5)" $(\mathrm{w}=0.31)$, "Easy access anywhere (SYQ3)" $(\mathrm{w}=0.19)$, "Ease of learning the System (SYQ1)" (w=0.18), "System response time (SYQ2)" $(\mathrm{w}=0.16)$, "Fast and efficient communication support (SYQ4)" $(\mathrm{w}=0.14)$.

The study believes that in the mobile health service system, when considering system quality, the "Security protection and system privacy (SYQ5)" should be seen in the top priority and taken into consideration. Subsequent reviews of "Easy access anywhere (SYQ3)" and "Ease of learning the System (SYQ1)" and "System response time (SYQ2)" and "Fast and effective communication support (SYQ4)" should be investigated and evaluated respectively. The results indicate that maintaining the security and privacy of the system is essential in order to raise the level of "system quality", which leads to better acceptance of the mobile health system by citizens. Nevertheless, this does not mean that other factors are not important enough, but this weight $(\mathrm{w}=0.31)$ of protecting privacy and privacy is far from the other factors, which indicates a very high need for this.

\section{- Information Quality (INQ)}

In the study of the sub-factors of the second main effective factor on information quality, $5 \mathrm{sub}$ factors of "Easy access to information (INQ1)", "Information is real-time (INQ2)", "Sufficient and relevant information (INQ3) ", "Accuracy of information (INQ4) ", and "Information is always updated (INQ5)" are examined.

Based on the analysis carried out, the sub factors below are ranked from the most important one to the least important as follows:

"Information is always updated (INQ5)" ( $\mathrm{w}=0.25)$, "Accuracy of information (INQ4)" (w=0.23), "Sufficient and relevant information (INQ3)" (w= $0.19)$, "Information is real-time (INQ2)" ( $\mathrm{w}=0.17)$, "Easy access to information (INQ1) (w=0.13)."

From the experts' point of view, the mentioned factors of the constant updating of information and then the accuracy of information are of higher priority. Then, sufficient and relevant information, real-time information and easy access to information is important and prioritized respectively.

\section{- Individual Factors (INF)}

Individual factors can be considered as one of the key criteria for adopting mobile health technology. In this study, four sub-factors of individual factors are considered as the third most important and effective factor in admission of mobile health including "Compatibility (INF1)", "Perceived usefulness (INF2)", "Perceived ease of use (INF3)", "Behavioral intend to use (INF4)".

Based on the analysis, the ranking of the following sub factors from the most important to the least important one is as follow: "Perceived ease of use (INF3)" ( $\mathrm{w}=0.29)$, "Perceived usefulness (INF2)" ( $\mathrm{w}=0.26)$, "Compatibility (INF1)" ( $\mathrm{w}=0.25)$, "Behavioral intend to use (INF4)" $(\mathrm{w}=0.21)$.

After weighting the sub-criteria of the individual factor, "Perceived ease of use" (INF3) can be considered in the first priority. There is not much difference in weight between "Compatibility (INF1)" and "Perceived usefulness (INF2)", ranked as the second. Finally, "Behavioral intention to use (INF4)" should be considered respectively. 


\section{- $\quad$ Service Quality (SEQ)}

Whereas service quality is less important in the results, the sub-criteria results can be controversial. One of the key factors in e-business that can continuously attract customer satisfaction is to improve service quality.

In this survey, four sub-criteria of service quality factors included the "Responsive system (SEQ1)", "Trusted system for service (SEQ2)", and "Ease of user service (SEQ3), Consistent service availability (SEQ4).

According to the evaluations carried out and extracted by expert, the following sub-criteria of service quality from the most important to the least one include "Trusted system for service (SEQ2)" ( $\mathrm{w}=0.39)$, "Responsive system (SEQ1)" $\quad(\mathrm{w}=0.22), \quad$ "Consistent service availability (SEQ4)" ( $(\mathrm{w}=0.19)$, "Ease of user service (SEQ3)" (w=0.18).

Among the services quality criteria, the trust issue, with the difference of other sub-criteria, is the priority of this main criterion. In the second step, 3 other sub criteria are "Responsive system (SEQ1)", "Consistent service availability (SEQ4)“, "Ease of user service (SEQ3). However, with little difference, they are prioritized.

\section{- Organizational (ORG)}

Finally, among the evaluations, the organizational criterion with the lowest value was reported, but the focus on this major factor also has significant implications for the acceptance of mobile health technology. 4 sub-factors of organizational factor include "Ability to adjust the information system (ORG1)", "Business process adjustment capability (ORG2)", “Top management support (ORG3), and IT staff ability (ORG4)".

In the final analysis, the organizational sub-factors, from the most important one to the least important are as follows: "Top management support (ORG3)" $(\mathrm{w}=0.32)$, "Ability to adjust the information system (ORG1)" (w= $0.25)$, "IT staff ability (ORG4)" (w=0.22), "Business process adjustment capability (ORG2)" ( $\mathrm{w}=0.19)$.

One of the effective factors on group success is the type of management and support required by management. According to the results of this study, and sub-factors of the organizational factors, "Top management support (ORG3)" is of great importance, and it should be taken seriously in launching mobile health system.

However, in the next mode, the factors of "Ability to adjust the information system (ORG1)", "IT staff ability (ORG4)", "Business process adjustment capability (ORG2)" were prioritized.

\section{DISCUSSION}

With regard to the momentous changes in the field of information technology around the world, this research aims to address the important issue of mobile health and to study its acceptance at the community level. Adopting mobile health in different societies can improve health, prevent many diseases, provide security, relax, save time, and have other benefits.

The development of mobile health, which is, in fact, the development of smart health, is also a puzzle of the smart city, helping us eventually have smart earth. On the other hand, with the advent of smart health, some concerns may arise from some physicians and health professionals. Generally, this study believes that the emergence of smart health is not a threat to the profession of physicians and their future careers. Instead, it is intended to help doctors improve health issues.

The research believes that the priority of mobile healthcare should be considered for certain and pandemic illnesses. For example, according to Batarseh and Latif [59], diabetes and blood pressure are two common illnesses in the United States that suffer many people, and if diabetes is not controlled, it can have a direct effect on blood pressure. Based on the results obtained in this study, mobile health can be used as the most reliable and safe tool for controlling and monitoring these diseases.

However, Handayani, Meigasari, Pinem, Hidayanto and Ayuningtyas [19] suggests that despite the growth of mobile health technology, the number of users utilizing this technology has not reached a significant level. It should not be forgotten that adopting mobile health in the younger group can institutionalize such a good technology in the family and community, since if mobile health is considered in the context of IT, then one can claim that the error is minimized and real-time accountability is also done. The Fuzzy AHP method, based on the linear programming priority, allows users to use fuzzy numbers to create a comparison matrix (Appendix. B). Furthermore, it can be used to determine the weight and rank of the main factors and their underlying factors.

\section{CONCLUSION}

The results indicated that adopting mobile health technology, along with the main factor of "System Quality (SYQ)" ( $w=0.24$ ) has a direct impact on the acceptance of mobile health technology. Additionally, two main factors "Information Quality (INQ)" (w=0.22) and "Individual factors (INF)" $(\mathrm{w}=0.21)$ help to improve and upgrade the system. In the following, the main factors of "Service Quality (SEQ)" (w=0.18), and "Organizational (ORG)" $(\mathrm{w}=0.15)$ were prioritized respectively. In general, the main factors of (INQ), (INF) (SYQ) were more important than (ORG) and (SEQ).

This analysis suggests that system quality factors, information, quality and individual factors are more effective in raising the acceptance factor of health technology than service quality and organizational factors. In the main (SYQ) factor, the sub factor of (SYQ5) ( $\mathrm{w}=$ 0.31 ) is different from other factors. Other factors are prioritized as SYQ3 ( $\mathrm{w}=0.19)$, (SYQ1) ( $\mathrm{w}=0.18)$, (SYQ2) $(\mathrm{w}=0.16),(\mathrm{SYQ} 4)(\mathrm{w}=0.14)$. This means maintaining the security and privacy of the system is of great importance.

Considering the main factor (INQ), the sub-factor $($ INQ5 $)=(\mathrm{w}=0.25)$, is more important than $($ INQ4 $)(\mathrm{w}=$ 
$0.23),(\mathrm{INQ} 3)(\mathrm{w}=0.19),(\mathrm{INQ} 2)(\mathrm{w}=0.17),(\mathrm{INQ} 1)(\mathrm{w}$ $=0.13$ ). It should be noted that the sub-factors of this factor do not have the much-weighted difference. It is evident here that the initial updating of information and then the accuracy of the information in the adoption of mobile health technology can make a significant contribution.

Regarding the main factor (INF), the sub-factor (INF3) $(\mathrm{w}=0.29)$ is in a priority than other sub-factors such as (INF2) $(\mathrm{w}=0.26),(\mathrm{INF} 1)(\mathrm{w}=0.25),(\mathrm{INF} 4)(\mathrm{w}=0.21)$. This means that understanding the sub-criterion (INF3) in the main factor of individual factors can be effective on accepting mobile health technology.

For factor (SEQ), the sub-factor (SEQ2) $(w=0.39)$ has a significant difference compared to other sub-criteria (SEQ1) $(\mathrm{w}=0.22),($ SEQ4) $(\mathrm{w}=0.19),(\mathrm{SEQ} 3)(\mathrm{w}=$ 0.18 ). Trust is a controversial issue, and here it is well known that serious attention should be paid to trust to accept mobile health.

Finally, the main factor (ORG), which is the last major criterion of this research model, had four sub-criteria which $(\mathrm{ORG} 3)(\mathrm{w}=0.32)$ is significantly different from the other sub-factors including (ORG1) ( $w=0.25)$, (ORG4) $(\mathrm{w}=0.22),(\mathrm{ORG} 2)(\mathrm{w}=0.19)$. It is obvious that in an organizational component, the sub-criterion of supportive management can enhance the motivation to accept mobile health technology.

Based on the results and comparing the main factors with the previous researches, four effective factors on the acceptance of mobile health services were investigated in one dimension of the society. Their results, with the first "System Quality (SYQ)" factor known as the main factor, achieved the highest rank in previous research and now have the highest importance in their community dimension and have been rising. The second factor of "Information Quality (INQ)" was the second-highest in the previous study and is now the second-highest in this research. The "Individual Factor (INF)" has been little mentioned in previous researches and it should be explored, but it is now the third most important factor in this research. The last two factors namely Service Quality (SEQ) and Organizational (ORG) have both been in the same range and have had a moderate impact on previous research as well as this study. This research has only examined some of the effective factors on admission to mobile health. Therefore, this article gives a glimpse of the adoption of mobile health technology to future researchers in this field. However, this study is not intended to be a comprehensive review, as it is small in a small statistical population with a limited number of experts and provides a relative view of the subject to the audience. On the other hand, in future research, the proposed model will be an applicable and acceptable.

This study achieved criteria to implement mobile health service acceptance systems. As reported in research [1], the medical sector is now integrated with information technology, and significant advances have been made in this area. These criteria had a great role in designing and implementing telemedicine applications and physicians have been able to treat and cure many diseases with these technologies. Using this method and ranking the criteria and gaining the weight of them, the effective criteria that need to be implemented in this category of medical applications can be gained. Fuzzy AHP Multi-Criteria Decision Making Methods were used to standardize and weight the criteria. Finally, Figure 3, which is the proposed model, illustrates mobile health service acceptance agents to prioritize the use of these types of services using the TAM 2 model, which is one of the founders of mobile health acceptance system. Finally, it was concluded that the Fuzzy AHP method has more flexibility and a higher ability to determine the appropriate criteria for the mobile health service acceptance system.

Additionally, the main finding of this research and the suggestion for future work is to get effective factors the better acceptance of mobile healthcare technology, it is not enough for those directly benefiting from this technology and the work report was taken from them, and to adopt a policy for this purpose or evaluate and investigate just experts' opinion in this regard since this is an epidemic issue and smart health is for all cities, and sooner or later this essential technology will be operational in advanced cities. Surveys, interviews, reviews, evaluations, and analyses should be carried out from different classes of the society, such as students, clinicians, and hospitals, etc. Finally, in a more comprehensive research, the results of these analyses should be evaluated in order to obtain the desired result.

\section{Funding}

The author(s) received no financial support for the research, authorship, and/or publication of this article.

\section{Conflict of Interest}

The authors have no potential conflicts of interest relevant to this article. 


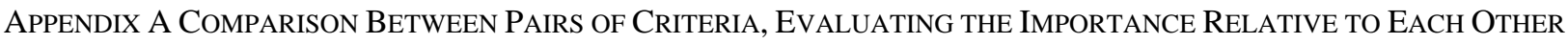 (A SAMPLE OF RESUlT OF EXPERT CONSENSUSES IN STEP 1).}

Descriptions about scales: 1= Equal, $2=$ Weakly important, $3=$ Strongly more important, $4=$ Very strongly important, $5=$ Extremely more important.

\begin{tabular}{|c|c|c|c|c|c|c|c|c|c|c|c|}
\hline $\mathrm{Q}$ & Main factor & \multicolumn{9}{|c|}{ Fuzzy scale } & Main factor \\
\hline Q1 & System Quality (SYQ) & 5 & 4 & 3 & 2 & 1 & 2 & 3 & 4 & 5 & Information Quality (INQ) \\
\hline \begin{tabular}{|l|l|} 
Q2 \\
\end{tabular} & System Quality (SYQ) & 5 & 4 & 3 & 2 & 1 & 2 & 3 & 4 & 5 & Individual factors (INF) \\
\hline Q3 & System Quality (SYQ) & 5 & 4 & 3 & 2 & 1 & 2 & 3 & 4 & 5 & Service Quality (SEQ) \\
\hline Q4 & System Quality (SYQ) & 5 & 4 & 3 & 2 & 1 & 2 & 3 & 4 & 5 & Organizational (ORG) \\
\hline Q5 & Information Quality (INQ) & 5 & 4 & 3 & 2 & 1 & 2 & 3 & 4 & 5 & Individual factors (INF) \\
\hline Q6 & Information Quality (INQ) & 5 & 4 & 3 & 2 & 1 & 2 & 3 & 4 & 5 & Service Quality (SEQ) \\
\hline Q7 & Information Quality (INQ) & 5 & 4 & 3 & 2 & 1 & 2 & 3 & 4 & 5 & Organizational (ORG) \\
\hline Q8 & Individual factors (INF) & 5 & 4 & 3 & 2 & 1 & 2 & 3 & 4 & 5 & Service Quality (SEQ) \\
\hline Q9 & Individual factors (INF) & 5 & 4 & 3 & 2 & 1 & 2 & 3 & 4 & 5 & Organizational (ORG) \\
\hline Q10 & Service Quality (SEQ) & 5 & 4 & 3 & 2 & 1 & 2 & 3 & 4 & 5 & Organizational (ORG) \\
\hline $\mathrm{Q}$ & Sub-factor & \multicolumn{9}{|c|}{ Fuzzy scale } & Sub-factor \\
\hline Q11 & Ease of learning the System (SYQ1) & 5 & 4 & 3 & 2 & 1 & 2 & 3 & 4 & 5 & System response time (SYQ2) \\
\hline Q12 & Ease of learning the System (SYQ1) & 5 & 4 & 3 & 2 & 1 & 2 & 3 & 4 & 5 & Easy access anywhere (SYQ3) \\
\hline Q13 & Ease of learning the System (SYQ1) & 5 & 4 & 3 & 2 & 1 & 2 & 3 & 4 & 5 & $\begin{array}{c}\text { Fast and efficient } \\
\text { communication support (SYQ4) }\end{array}$ \\
\hline Q14 & Ease of learning the System (SYQ1) & 5 & 4 & 3 & 2 & 1 & 2 & 3 & 4 & 5 & Security protection and system privacy (SYQ5) \\
\hline Q15 & System response time (SYQ2) & 5 & 4 & 3 & 2 & 1 & 2 & 3 & 4 & 5 & Easy access anywhere (SYQ3) \\
\hline Q16 & System response time (SYQ2) & 5 & 4 & 3 & 2 & 1 & 2 & 3 & 4 & 5 & $\begin{array}{c}\text { Fast and efficient } \\
\text { communication support (SYQ4) }\end{array}$ \\
\hline Q17 & System response time (SYQ2) & 5 & 4 & 3 & 2 & 1 & 2 & 3 & 4 & 5 & Security protection and system privacy (SYQ5) \\
\hline Q18 & Easy access anywhere (SYQ3) & 5 & 4 & 3 & 2 & 1 & 2 & 3 & 4 & 5 & $\begin{array}{c}\text { Fast and efficient } \\
\text { communication support (SYQ4) }\end{array}$ \\
\hline Q19 & Easy access anywhere (SYQ3) & 5 & 4 & 3 & 2 & 1 & 2 & 3 & 4 & 5 & Security protection and system privacy (SYQ5) \\
\hline Q20 & Fast and efficient communication support (SYQ4) & 5 & 4 & 3 & 2 & 1 & 2 & 3 & 4 & 5 & Security protection and system privacy (SYQ5) \\
\hline Q21 & Easy access to information (INQ1) & 5 & 4 & 3 & 2 & 1 & 2 & 3 & 4 & 5 & Information is real-time (INQ2) \\
\hline Q22 & Easy access to information (INQ1) & 5 & 4 & 3 & 2 & 1 & 2 & 3 & 4 & 5 & Sufficient and relevant Information (INQ3) \\
\hline Q23 & Easy access to information (INQ1) & 5 & 4 & 3 & 2 & 1 & 2 & 3 & 4 & 5 & Accuracy of Information (INQ4) \\
\hline Q24 & Easy access to information (INQ1) & 5 & 4 & 3 & 2 & 1 & 2 & 3 & 4 & 5 & Information is always Updated(INQ5) \\
\hline Q25 & Information is real-time (INQ2) & 5 & 4 & 3 & 2 & 1 & 2 & 3 & 4 & 5 & Sufficient and relevant Information (INQ3) \\
\hline Q26 & Information is real-time (INQ2) & 5 & 4 & 3 & 2 & 1 & 2 & 3 & 4 & 5 & Accuracy of Information (INQ4) \\
\hline Q27 & Information is real-time (INQ2) & 5 & 4 & 3 & 2 & 1 & 2 & 3 & 4 & 5 & Information is always Updated(INQ5) \\
\hline Q28 & Sufficient and relevant Information (INQ3) & 5 & 4 & 3 & 2 & 1 & 2 & 3 & 4 & 5 & Accuracy of Information (INQ4) \\
\hline Q29 & Sufficient and relevant Information (INQ3) & 5 & 4 & 3 & 2 & 1 & 2 & 3 & 4 & 5 & Information is always Updated (INQ5) \\
\hline Q30 & Accuracy of Information (INQ4) & 5 & 4 & 3 & 2 & 1 & 2 & 3 & 4 & 5 & Information is always Updated (INQ5) \\
\hline Q31 & Compatibility (INF1) & 5 & 4 & 3 & 2 & 1 & 2 & 3 & 4 & 5 & Perceived usefulness (INF2) \\
\hline Q32 & Compatibility (INF1) & 5 & 4 & 3 & 2 & 1 & 2 & 3 & 4 & 5 & Perceived ease of use (INF3) \\
\hline Q33 & Compatibility (INF1) & 5 & 4 & 3 & 2 & 1 & 2 & 3 & 4 & 5 & Behavioral intend to use (INF4) \\
\hline Q34 & Perceived usefulness (INF2) & 5 & 4 & 3 & 2 & 1 & 2 & 3 & 4 & 5 & Perceived ease of use (INF3) \\
\hline Q35 & Perceived usefulness (INF2) & 5 & 4 & 3 & 2 & 1 & 2 & 3 & 4 & 5 & Behavioral intend to use (INF4) \\
\hline Q36 & Perceived ease of use (INF3) & 5 & 4 & 3 & 2 & 1 & 2 & 3 & 4 & 5 & Behavioral intend to use (INF4) \\
\hline Q37 & Responsive system (SEQ1) & 5 & 4 & 3 & 2 & 1 & 2 & 3 & 4 & 5 & Trusted system for service (SEQ2) \\
\hline Q38 & Responsive system (SEQ1) & 5 & 4 & 3 & 2 & 1 & 2 & 3 & 4 & 5 & Ease of user service (SEQ3) \\
\hline Q39 & Responsive system (SEQ1) & 5 & 4 & 3 & 2 & 1 & 2 & 3 & 4 & 5 & Consistent service availability (SEQ4) \\
\hline Q40 & Trusted system for service (SEQ2) & 5 & 4 & 3 & 2 & 1 & 2 & 3 & 4 & 5 & Ease of user service (SEQ3) \\
\hline Q41 & Trusted system for service (SEQ2) & 5 & 4 & 3 & 2 & 1 & 2 & 3 & 4 & 5 & Consistent service availability (SEQ4) \\
\hline Q42 & Ease of user service (SEQ3) & 5 & 4 & 3 & 2 & 1 & 2 & 3 & 4 & 5 & Consistent service availability (SEQ4) \\
\hline Q43 & Ability to adjust the information system (ORG1) & 5 & 4 & 3 & 2 & 1 & 2 & 3 & 4 & 5 & Business process adjustment capability (ORG2) \\
\hline Q44 & Ability to adjust the information system (ORG1) & 5 & 4 & 3 & 2 & 1 & 2 & 3 & 4 & 5 & Top management support (ORG3) \\
\hline Q45 & Ability to adjust the information system (ORG1) & 5 & 4 & 3 & 2 & 1 & 2 & 3 & 4 & 5 & IT staff ability (ORG4) \\
\hline Q46 & Business process adjustment capability (ORG2) & 5 & 4 & 3 & 2 & 1 & 2 & 3 & 4 & 5 & Top management support (ORG3) \\
\hline Q47 & Business process adjustment capability (ORG2) & 5 & 4 & 3 & 2 & 1 & 2 & 3 & 4 & 5 & IT staff ability (ORG4) \\
\hline Q48 & Top management support (ORG3) & 5 & 4 & 3 & 2 & 1 & 2 & 3 & 4 & 5 & IT staff ability (ORG4) \\
\hline
\end{tabular}


APPENDIX B FUZZY NUMBER PAIRWISE COMPARISON MATRIX.

\begin{tabular}{cccccc}
\hline & SYQ & INQ & INF & SEQ & ORG \\
\hline SYQ & $(1,1,1)$ & $(3,5,7)$ & $(0.14,0.2,0.33)$ & $(5,7,9)$ & $(3,5,7)$ \\
INQ & $(0.14,0.2,0.33)$ & $(1,1,1)$ & $(3,5,7)$ & $(3,5,7)$ & $(1,3,5)$ \\
INF & $(3,5,7)$ & $(0.14,0.2,0.33)$ & $(1,1,1)$ & $(3,5,7)$ & $(1,1,1)$ \\
SEQ & $(0.11,0.14,0.0 .2)$ & $(0.14,0.2,0.33)$ & $(0.14,0.2,0.33)$ & $(1,1,1)$ & $(3,5,7)$ \\
ORG & $(0.14,0.2,0.33)$ & $(0.2,0.33,1)$ & $(1,1,1)$ & $(0.14,0.2,0.33)$ & $(1,1,1)$ \\
\hline
\end{tabular}

\section{REFERENCES}

[1] M. I. Pramanik, R. Y. Lau, H. Demirkan, and M. A. K. Azad, "Smart health: Big data enabled health paradigm within smart cities," Expert Systems with Applications, vol. 87, pp. 370-383, 2017.

[2] C. Röcker, M. Ziefle, and A. Holzinger, "From computer innovation to human integration: current trends and challenges for pervasive HealthTechnologies," Pervasive health, pp. 1-17: Springer, 2014.

[3] C. M. Clancy, "Getting to 'smart'health care," Health Affairs, vol. 25, no. 6, pp. 589-592, 2006.

[4] G. Peng, D. Dey, and A. Lahiri, "Healthcare IT adoption: An analysis of knowledge transfer in socioeconomic networks," Journal of Management Information Systems, vol. 31, no. 3, pp. 7-34, 2014.

[5] U. Varshney, "Pervasive healthcare," Computer, vol. 36, no. 12, pp. 138-140, 2003

[6] U. Varshney, "Pervasive healthcare and wireless health monitoring," Mobile Networks and Applications, vol. 12, no. 2-3, pp. 113-127, 2007.

[7] C. E. Begley, D. Lairson, R. O. Morgan, P. J. Rowan, and R. Balkrishnan, Evaluating the healthcare system: effectiveness, efficiency, and equity: Health Administration Press Chicago, 2013.

[8] A. K. Jha, T. G. Ferris, K. Donelan, C. DesRoches, A. Shields, S. Rosenbaum, and D. Blumenthal, "How Common Are Electronic Health Records In The United States? A Summary Of The Evidence: About one-fourth of US physician practices are now using an EHR, according to the results of high-quality surveys," Health Affairs, vol. 25, no. Suppl1, pp. W496-W507, 2006.

[9] Ofcom., "UK Commuications: Fast facts," 2013.

[10] J. H. West, P. C. Hall, C. L. Hanson, M. D. Barnes, C. Giraud-Carrier, and J. Barrett, "There's an app for that: content analysis of paid health and fitness apps," Journal of medical Internet research, vol. 14, no. 3, pp. e72, 2012.

[11] S. Kumar, W. J. Nilsen, A. Abernethy, A. Atienza, K. Patrick, M. Pavel, W. T. Riley, A. Shar, B. Spring, D. Spruijt-Metz, D. Hedeker, V. Honavar, R. Kravitz, R. C. Lefebvre, D. C. Mohr, S. A. Murphy, C. Quinn, V. Shusterman, and D. Swendeman, "Mobile health technology evaluation: the mHealth evidence workshop," Am J Prev Med, vol. 45, no. 2, pp. 228-36, Aug, 2013.

[12] J. Li, L. P. W. Land, S. Chattopadhyay, and P. Ray, "EHealth readiness framework from Electronic Health Records perspective," GlobDev 2008, pp. 4, 2008.

[13] M. Eichelberg, T. Aden, J. Riesmeier, A. Dogac, and G. B. Laleci, "A survey and analysis of electronic healthcare record standards," Acm Computing Surveys (Csur), vol. 37, no. 4, pp. 277-315, 2005.

[14] B. Martínez-Pérez, I. De La Torre-Díez, M. LópezCoronado, and J. Herreros-González, "Mobile apps in cardiology," JMIR mHealth and uHealth, vol. 1, no. 2, pp. e15, 2013.

[15] P. Zuehlke, J. Li, A. Talaei-Khoei, and P. Ray, "A functional specification for mobile eHealth (mHealth) Systems." pp. 74-78.

[16] B. M. Silva, J. J. Rodrigues, I. de la Torre Díez, M. López-Coronado, and K. Saleem, "Mobile-health: A review of current state in 2015," Journal of biomedical informatics, vol. 56, pp. 265-272, 2015.

[17] K. D. Bowers, A. Juels, and A. Oprea, "HAIL: A highavailability and integrity layer for cloud storage." pp. 187198.

[18] M. Fiordelli, N. Diviani, and P. J. Schulz, "Mapping mHealth research: a decade of evolution," Journal of medical Internet research, vol. 15, no. 5, pp. e95, 2013.

[19] P. W. Handayani, D. A. Meigasari, A. A. Pinem, A. N. Hidayanto, and D. Ayuningtyas, "Critical success factors for mobile health implementation in Indonesia," Heliyon, vol. 4, no. 11, pp. e00981, 2018.

[20] J. Mezei, and S. Nikou, "Fuzzy optimization to improve mobile wellness applications for young-elderly." p. 14.

[21] M. Esposito, A. Minutolo, R. Megna, M. Forastiere, M. Magliulo, and G. De Pietro, "A smart mobile, selfconfiguring, context-aware architecture for personal health monitoring," Engineering Applications of Artificial Intelligence, vol. 67, pp. 136-156, 2018.

[22] S. El-Sappagh, M. Elmogy, and A. Riad, "A fuzzyontology-oriented case-based reasoning framework for semantic diabetes diagnosis," Artificial intelligence in medicine, vol. 65, no. 3, pp. 179-208, 2015.

[23] J. Mezei, and S. Nikou, "Fuzzy optimization to improve mobile health and wellness recommendation systems," Knowledge-Based Systems, vol. 142, pp. 108-116, 2018.

[24] N. H. Phuong, and V. Kreinovich, "Fuzzy logic and its applications in medicine," International journal of medical informatics, vol. 62, no. 2-3, pp. 165-173, 2001.

[25] K. K. Oad, X. DeZhi, and P. K. Butt, "A fuzzy rule based approach to predict risk level of heart disease," Global Journal of Computer Science and Technology, 2014.

[26] K.-S. Chuang, H.-L. Tzeng, S. Chen, J. Wu, and T.-J. Chen, "Fuzzy c-means clustering with spatial information for image segmentation," computerized medical imaging and graphics, vol. 30, no. 1, pp. 9-15, 2006.

[27] D. Nauck, and R. Kruse, "Obtaining interpretable fuzzy classification rules from medical data," Artificial intelligence in medicine, vol. 16, no. 2, pp. 149-169, 1999.

[28] D. Zhang, K. Du, and L. Sun, "A fuzzy logic based context-aware reminder for elders with mild dementia."

[29] F.-M. E. Uzoka, J. Osuji, F. O. Aladi, and O. U. Obot, "A framework for cell phone based diagnosis and management of priority tropical diseases." pp. 1-13.

[30] E. Jeon, and H. Park, "Factors affecting acceptance of smartphone application for management of obesity," Healthcare informatics research, vol. 21, no. 2, pp. 74-82, 2015.

[31] U. Varshney, "Mobile health: Four emerging themes of research," Decision Support Systems, vol. 66, pp. 20-35, 2014. 
[32] A. M. Cohen, C. E. Adams, J. M. Davis, C. Yu, P. S. Yu, W. Meng, L. Duggan, M. McDonagh, and N. R. Smalheiser, "Evidence-based medicine, the essential role of systematic reviews, and the need for automated text mining tools." pp. 376-380.

[33] D. R. Compeau, and C. A. Higgins, "Computer selfefficacy: Development of a measure and initial test," MIS quarterly, pp. 189-211, 1995.

[34] J.-H. Wu, S.-C. Wang, and L.-M. Lin, "Mobile computing acceptance factors in the healthcare industry: A structural equation model," International journal of medical informatics, vol. 76, no. 1, pp. 66-77, 2007.

[35] R. Haux, "Health information systems-past, present, future," International journal of medical informatics, vol. 75, no. 3-4, pp. 268-281, 2006.

[36] C. M. Johnson, and J. P. Turley, "The significance of cognitive modeling in building healthcare interfaces," International journal of medical informatics, vol. 75, no. 2, pp. 163-172, 2006.

[37] W. H. Delone, and E. R. McLean, "The DeLone and McLean model of information systems success: a ten-year update," Journal of management information systems, vol. 19, no. 4, pp. 9-30, 2003.

[38] D. Buhalis, "eAirlines: strategic and tactical use of ICTs in the airline industry," Information \& Management, vol. 41, no. 7, pp. 805-825, 2004.

[39] R. Santhanam, and E. Hartono, "Issues in linking information technology capability to firm performance," MIS quarterly, pp. 125-153, 2003.

[40] P. Keikhosrokiani, N. Mustaffa, N. Zakaria, and M. I. Sarwar, "Wireless positioning techniques and locationbased services: a literature review," Multimedia and Ubiquitous Engineering, pp. 785-797: Springer, 2013.

[41] C. Bossen, L. G. Jensen, and F. W. Udsen, "Evaluation of a comprehensive EHR based on the DeLone and McLean model for IS success: approach, results, and success factors," International journal of medical informatics, vol. 82, no. 10, pp. 940-953, 2013.

[42] E. Ahmed, M. N. Ahmad, and S. Othman, "Health information system critical success factors (HISCFs): a systematic literature review," J. Inf. Syst. Res. Innov, vol. 10, no. 1, pp. 29-39, 2016.

[43] S. Chatterjee, S. Chakraborty, S. Sarker, S. Sarker, and F. Y. Lau, "Examining the success factors for mobile work in healthcare: A deductive study," Decision Support Systems, vol. 46, no. 3, pp. 620-633, 2009.

[44] M. Falasca, and J. F. Kros, "Success factors and performance outcomes of healthcare industrial vending systems: an empirical analysis," Technological Forecasting and Social Change, vol. 126, pp. 41-52, 2018.

[45] E. M. Rogers, "Diffusion of Innovations. Simon \& Shuster,"Inc., 2003.

[46] S.-Y. Hung, C. Chen, and K.-H. Wang, "Critical success factors for the implementation of integrated healthcare information systems projects: An organizational fit perspective," Communications of the Association for Information Systems, vol. 34, no. 1, pp. 39, 2014.

[47] Y. Zhang, J. Zhang, and J. Chen, "Critical success factors in IT service management implementation: People, process, and technology perspectives." pp. 64-68.

[48] F. Meng, X. Guo, Z. Peng, X. Zhang, and D. Vogel, "The routine use of mobile health services in the presence of health consciousness," Electronic Commerce Research and Applications, vol. 35, pp. 100847, 2019.
[49] T. L. Saaty, "The analytic hierarchy process McGrawHill," New York, vol. 324, 1980.

[50] C. Kahraman, U. Cebeci, and D. Ruan, "Multi-attribute comparison of catering service companies using fuzzy AHP: The case of Turkey," International journal of production economics, vol. 87, no. 2, pp. 171-184, 2004.

[51] R. Zhao, and R. Govind, "Algebraic characteristics of extended fuzzy numbers," Information Sciences, vol. 54, no. 1-2, pp. 103-130, 1991.

[52] N. Badie, A. R. C. Hussin, and A. H. Lashkari, "Cloud computing data center adoption factors validity by fuzzy AHP," International Journal of Computational Intelligence Systems, vol. 8, no. 5, pp. 854-873, 2015.

[53] P. T. M. Ly, W.-H. Lai, C.-W. Hsu, and F.-Y. Shih, "Fuzzy AHP analysis of Internet of Things (IoT) in enterprises," Technological Forecasting and Social Change, vol. 136, pp. 1-13, 2018.

[54] Y.-M. Wang, and K.-S. Chin, "Fuzzy analytic hierarchy process: A logarithmic fuzzy preference programming methodology," International Journal of Approximate Reasoning, vol. 52, no. 4, pp. 541-553, 2011.

[55] A. H. Lashkari, A. A. Manaf, and M. Masrom, "Graphical password security evaluation by fuzzy AHP," World Academy of Science, Engineering and Technology, vol. 66, 2012.

[56] G. Büyüközkan, C. Kahraman, and D. Ruan, “A fuzzy multi-criteria decision approach for software development strategy selection," International Journal of General Systems, vol. 33, no. 2-3, pp. 259-280, 2004.

[57] F. A. Haery, H. Ghorbani, and A. A. Farahmand, "An AHP approach for ranking critical success factors of customers experience in Iranian banks from managers' viewpoint," International Journal of Marketing Studies, vol. 6, no. 1, pp. 168, 2014.

[58] A. T. Gumus, "Evaluation of hazardous waste transportation firms by using a two step fuzzy-AHP and TOPSIS methodology," Expert systems with applications, vol. 36, no. 2, pp. 4067-4074, 2009.

[59] F. A. Batarseh, and E. A. Latif, "Assessing the quality of service using big data analytics: with application to healthcare," Big Data Research, vol. 4, pp. 13-24, 2016.

\section{Authors' Profiles}

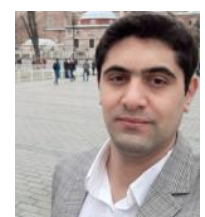

Farhad Lotfi- born in 1990 in Tehran, Iran-is an M.Sc. of Information Technology Engineering at the Islamic Azad University, South Tehran Branch, Department of Information Technology Engineering. His research interests are Smart Healthcare and Soft Computing. Currently, he is a researcher at Young Researchers and Elite Club at Islamic Azad University, South Tehran Branch.

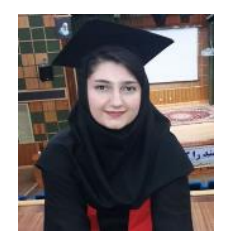

Kimia Fatehi- received the M.Sc. of Information Technology Engineering from the Islamic Azad University, South Tehran Branch, Department of Information Technology Engineering. Her research interests are Smart Healthcare and Soft Computing. Currently, she is a researcher at Young Researchers and Elite Club at Islamic Azad University, South Tehran Branch. 
Nasrin Badie received the M.Sc. and Ph.D. in Information Technology from University Technology Malaysia, Johor, Malaysia, in 2011 and 2015 respectively. During her Ph.D. she held international fellowships in 20122015. Her research interest is Cloud Computing Management with the applications in Machine Learning. She is currently a senior lecture at Department of Information Technology Software Development, School of Engineering, West Tehran Islamic Azad University. She has several articles in the Clarivate Analytics.

How to cite this paper: Farhad Lotfi, Kimia Fatehi, Nasrin Badie, "An Analysis of Key Factors to Mobile Health Adoption using Fuzzy AHP", International Journal of Information Technology and Computer Science(IJITCS), Vol.12, No.2, pp.1-17, 2020. DOI: 10.5815/ijitcs.2020.02.01 